two long focus microscopes, whose axes produced intersect the divided circle at the extremities of a diameter. They are read by means of a pointer and spider-line micrometer, whose head is divided into 300 parts, each of which represent; one second of arc. The microscopes are carried at such a height that they easily pass the collimator, and they can be read in any position, and the light from the collimator passes clear under the girder.

J. E. A. StegGali

THE ABACUS IN EUROPE AND THE EAST

$\mathrm{A}^{\mathrm{T}}$ a late meeting of the Asiatic Society of Japan (reported in the Fapan Mail), Dr. Knott read a paper on "The Abacus, and its Scientific and Historic Import." A portion of the paper described the various arithmetical processes connected with the soroban, the form of the abacus employed in Japan. The writer pointed out that in all arithmetical operations up to the extraction of the cube root, the soroban really possessed distinct advantages over ordinary ciphering. This in itself explained why the instrument, which in Europe is suggestive of an infant school, has in the East survived till the present day. The rest of the paper was a discussion of the peculiar position which the abacus, used in its widest signification, holds in the history of the progress of arithmetic and mathematics, and of science and civilisation generally. The following is an abstract of the argument, the ultimate object of which was to explain why the abacus had died in Europe but lived in China, and why the cipher system of numerals had grown up in India but not in China.

The abacus, as used in China and Japan, bears, on the surface of it, evidence of a foreign origin. The numbers are set down on it with the larger denomination to the left-a method which could hardly be believed to have been invented by the Chinese, who tend to work from right to left, and who have always named their compound numbers beginning with the higher denominations. The Chinaman says "one hundred forty-five," as the Englishman does ; but the Englishman once said "one hundred five-and-forty," as the German still does; while in some of the Aryan languages of India, and in the Arabic of to-day, the number is named "five-and-forty and one hundred." The Arab writes from right to left, so that, had the abacus been invented by such a people who, so to speak, both wrote and spoke inversely, it would have indicated the number as it does. In fact, the abacus could only have arisen in its present form amongst a people who either wrote and spoke directly, or wrote and spoke inversely. As a matter of history, the geographical home of the abacus is India, but, unless there is conclusive evidence to the contrary, we cannot regard it as an invention of Aryan Indians, who, although they wrote directly, spoke inversely. They probably borrowed it from the Semitic merchants, and these, with their inverse speaking and inverse writing, may have invented it, or perhaps received it from a direct-speaking, direct-writing people, such as the highly-cultured Accadians seem to have been. The abacus was evolved, no doubt, from the human hand, which, with its ten fingers, was the only counting-board used by primitive man. Its course of development is quite distinct from that of the symbolic representation of numbers. These latter we can trace through four stages, which may be called the pictorial, the symbolic, the decimal, and the cipher. The pictorial we find in the Egyptian hieroglyphic and the Accadian cuneiform ; the symbolic in the hieratic, Phœnician, Hebrew, Greek, Roman, and the host of systems which grew up with the development and spread of alphabets and syllabaries, and the decimal in the simplification of these which live to-day in the Chinese and Tamilic systems. Once the decimal stage was reached, its general similarity to the abacus indications suggested bringing them into still closer correspondence. This took place amongst the Aryan Indians, who, along with their brethren of the West, very soon discarded the abacus for the, to them, more convenient cipher notation. With the Chinese and Tamils, however, no advance was made in this direction, a fact especially surprising in the case of the latter, who have lived in close contact with peoples that have long used the cipher system of numerals. One reason for the Chinese conservatism in so adhering to an unwieldy notation might be their vertical mode of writing, with which no very striking similarity between their symbolising of numbers and the abacus columns would appear. But this does not explain the conservatism of the Tamils, who write from left to right, nor yet the persistence of the abacus for centuries face to face with the Indian cipher system. The explanation is rather to be found in the system of nomenclature, which, being direct both among the Chinese and the Tamils, fitted perfectly with the abacus indications. For this reason the manipulation of the abacus in China and Japan is more rapid and certain than ciphering, and hence, there being no advantage for simple arithmetical operations in tne latter, the cipher system did not develop in these countries, and even when introduced from the West in all its vigour could not displace "the rod and the beads." An Aryan Indian, with his inverse-speaking, could never work the abacus with the same facility as the Japanese unless he worked from right to left, a mode of procedure quite foreign to his nature. It is not so foreign to the Chinese and Japanese, however, to work from left to right, as shown in the formation of each individual ideograph employed in writing. Hence the abacus suited the Chinese language better than it did any of the Aryan languages in their original mode of numbernaming. The influence of the notation which was developed from Semitic sources under the influence of the abacus, has in later times compelled many of the Aryan languages to assimilate as far as possible to the direct mode of numeration; but in the English fifteen, the German fünfzehn, and the French quinze, we still have the relics of the original inverse mode of naming, alike peculiar to Aryan and Semitic peoples.

In the course of the discussion which followed, it was mentioned that Chinese mathematics were first studied in Japan about 900 A.D., and that the Japanese ascend by powers of Io, 000 in their treatment of larger numbers.

\section{THE GAZETTEER OF RUSSIA}

$W^{E}$ have received the concluding fascicule of the "Geographical and Statistical Dictionary of the Russian Empire," published by the Russian Geographical Society, and edited by M. P. Semenoff. This monumental work, which was begun more than twenty years ago, has been now concluded in five large octavo volumes, and will remain for many years the most trustworthy and c smplete source of information for the geography of the empire, exclusive of Poland, but inclusive of the former Russian dominions in America. It may be regretted that the editor of the "Dictionary" has been diverted by so great a variety of gengraphical, statistical, and administrative work from this undertaking, and that therefore the last fascicule appearing twenty-three years after the first, the statistical information contained in the first fascicules and volumes has become out of date. But notwithstanding that, the "Dictionary" has not become old. Its value is not in the statistical data it contains; it is much more in the excellent geographical descriptions of the localities treated-that is, of each separate government of Russia, Siberia, Turkestan, and Caucasus-of the seas that border Russia, and their islands. Several articles are excellent and most complete monographs, and we need only mention those on the Amur, Caucasus, Sakhalin, the Northern Ocean, or Turkestan to remind geographers of these excellent descriptions of whole regions. The geology, the flora and fauna of each region have received much attention. These descriptions will not soon be old--they can be only conipleted.

At the end of each article there is, moreover, a most complete bibliography of the larger geographical works in which the place described in the article has been mentioned, as also of monographs dealing with it, and of newspaper articles. This bibliography is invaluable for the geographer. On the whole, the equally high standard of all geographical descriptions and the unity of conception in all of them-the whole being the work of the editor himself, assisted only by M. Zverinsky and very few occasional contributors--make this "Dictionary" occupy one of the first ranks among like publications. An appendix is promised, which will contain descriptions of such regions as the Thian-Shan, Ferganah, and Transbaikalia, which were much explored during the publication of the "Dictionary." They will embody all recent information.

\section{UNIVERSITY AND EDUCATIONAL INTELLIGENCE}

Con vocation of the University of London met on Tuesday evening to consider the report of a Special Committee which proposed several important changes in the constitution of the

I “Geographitchesko-Statistitcheskiy Slovar Rossiyskoy Imperii,' P. P. Semenova. 